\title{
A NEW TECHNIQUE TO PREDICT MULTILAYERED RESERVOIR CHARACTERISTICS USING PULSE TESTING DATA
}

\author{
Mohammed E. Osman* and Sabry A. Mohammed** \\ * Professor, Department of Chemical and Petroleum Engineering \\ UAE University, Al-Ain, UAE \\ ** ZADCO, Abu Dhabi, UAE
}

\begin{abstract}
In this study, a mathematical model was developed to present pulse and interference testing for multilayered reservoirs. It was found that apparent storage calculated from pulse testing data is always less than or equal to the actual storage of the reservoir and that apparent transmissibility is always greater than or equal to the actual transmissibility. For short cycle intervals, the fractional production rate from a particular layer is not proportional to its transmissibility fraction. The effect of storage variation on fractional production rate is negligible. Wellbore damage affects both apparent transmissibility and storage. Less accurate estimation reservoir characteristics is obtained using pulse-test data as the contrast in reservoir properties increases and vice versa. A new approach is suggested to use data of single well test as well pulse test to estimate properties of individual layers. The approach is demonstrated by a three-layer numerical example.
\end{abstract}

\section{NOMENCLATURE}

A \& B : factors to correlate transmissibility and storage of layer $\mathrm{j}$ those of the system.

$f_{j} \quad:$ fractional production rate from (or injection into) layer $j$

n : pulse number

$\mathrm{N}:$ : number of layers

$\mathbf{P}_{\mathrm{Dj}} \quad$ : dimensionless pressure in layer $\mathbf{j}$

$P_{\text {Drj }}$ : dimensionless pressure amplitude opposite layer $\mathbf{j}$ in responding well

$\Delta \mathrm{p} \quad$ : pressure change, $\mathrm{psi}$

$\Delta \mathrm{p}_{\mathrm{j}} \quad$ : pressure change in pulsing well opposite layer $\mathrm{j}$

$\Delta \mathrm{p}_{\mathrm{rj}} \quad$ : pressure change in responding well opposite layer $\mathrm{j}$ 


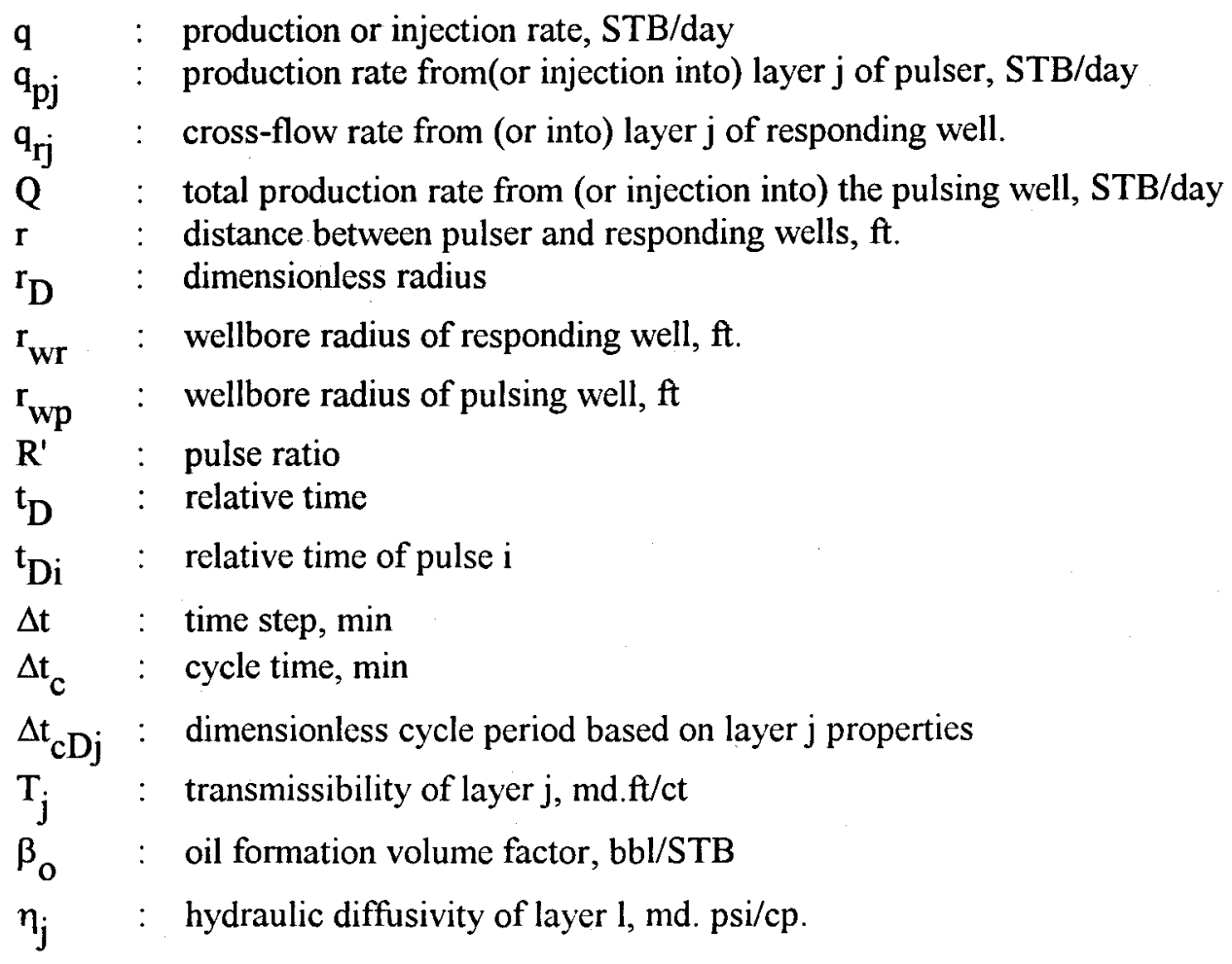

\section{INTRODUCTION}

Pulse testing is one of the most widely used techniques to predict interwell reservoir characteristics such as porosity and permeability. Johnson et al [1] presented a technique to predict the reservoir properties between two wells or more. One of them is used as a pulser and the others are used as observers. The pulser is activated by changing flow rate to create a transient pressure disturbance. In the same time, very sensitive pressure gauges are used to measure pressure response at the observers. Johnson et al [1] used such pulse testing data to estimate formation transmissibility and storage. Vela and McKinley [2] and Prats and Scott [3] investigated the effects of areal heterogeneities and wellbore storage on pulse testing data. Woods [4] proposed a method to estimate two zone reservoir characteristics using single well and pulse testing data. He found that apparent transmissibility obtained by pulse testing is always equal to or greater than the total transmissibility of the two zones and that apparent storage is always equal to or less than the total storage of the two zones. Correlation curves for pulse testing design and interpretation were developed by Brigham [5] for equal pulse and shut-in periods. A set of correlation curves was developed by Kamal and Brigham [6] for unequal 
pulse and shut-in periods. Such correlation can be used to optimize pulse ratio such that maximum response amplitude is obtained. Many applications of multi-well testing were reported in literature [7-10]. Al-Khalifah et al [11] presented a revision for Kàmal and Brigham [6] pulse testing correlation charts. El-Khatib [12] presented new correlation's for time lags and pressure response amplitude in pulsetest Analysis. For heterogeneous reservoirs, the use of numerical reservoir simulators has been used to interpret interwell pressure tests. However, some analytical models [13-15] were developed to interpret such testing data in layered reservoirs. Kaneda et al [16] used one of such models (Bourdet's Model [15]) to interpret a pulse test data obtained from one of Abu Dhabi reservoirs. They used a numerical simulator to modify the pulse test data to suit the analytical model of a two-layer system. They concluded that conventional pulse-test interpretation methods couldn't be satisfactorily applied to the pressure response in a two-layer system.

The literature review indicates that no reliable technique is available to interpret pulse-testing data of multilayered reservoirs. The main aim of this study is to handle such problem. Mathematical formulation is presented for multilayer systems and correlation charts were developed for two-layer system. An example is used to demonstrate the use of the technique presented in this study.

\section{MATHEMATICAL FORMULATION}

The reservoir understudy consists of $\mathrm{N}$-layers communicating only at wellbores. Each layer is homogeneous, horizontal, isotropic and fully filled with a fluid of small and constant compressibility. Two wells fully penetrate the reservoir. One of them is a pulser located at a distance $r$ from the other well, which is used as a responding well. The reservoir is an infinite acting and initially at a constant pressure. The reservoir and fluid properties vary from layer to layer. The pressure response at the observation well is due to the effect of production (or injection) at the pulser and the effect of cross flow between layers through the observation well. Line source solution is written for layer at the end of time step $1(\Delta t)$ as:

$$
\begin{aligned}
\Delta P(t)_{r j}= & -70.6 \frac{q_{p j} \beta_{o}}{T_{j}} \operatorname{Ei}\left(\frac{-56900 S_{j} r^{2}}{T_{j} \Delta t}\right) \\
& -70.6 \frac{q_{r j} \beta_{o}}{T_{j}} \operatorname{Ei~}\left(\frac{-56900 S_{j} r^{2} w r}{T_{j} \Delta t}\right) \quad j=1,2, \ldots N
\end{aligned}
$$

since the second Ei term superimposes the pressure response due to crossflow upon the pressure response due to production (or injection) at the pulser, the observed 
pressure response at the responding well corresponds to pulses as in the case of a single zone reservoir.

Similarly, pressure change at the pulser is due to production from (or injection into) the pulser and cross flow between layers through the responding wells. It is written as:

$$
\begin{aligned}
\Delta P(t)_{P j}= & -70.6 \frac{q_{p j}}{T_{j}} \operatorname{Ei}\left(\frac{-56900 S_{j} r^{2} w p}{T_{j} \Delta t}\right) \\
& -70.6 \frac{q_{r}}{T_{j}} \operatorname{Ei}\left(\frac{-56900 S_{j} r^{2}}{T_{j} \Delta t}\right) \quad j=1,2, \ldots N
\end{aligned}
$$

Equations (1) and (2) contain four sets of unknowns $\mathrm{q}_{\mathrm{pj}}$ (production or injection at pulser in layer $j$ ), $q_{r j}$ (cross flow between layer $j$ and the other layers at the responding well) and $\Delta \mathrm{p}_{\mathrm{rj}}$ and $\Delta \mathrm{p}_{\mathrm{pj}}$ (pressure change at responding and pulsing wells due to pulses in layer $\mathrm{j}$ ). The sum of the individual zone rates at any instant time must equal to the known total production (or injection) rate at the pulser:

$$
\sum_{j=1}^{N} q_{p j}=Q
$$

Also, since there is no external production (or injection) at the responding well, the cross flow rate out of any zone must equal to the cross flow rate into the other zones; thus:

$$
\sum_{j=1}^{N} q_{r j}=0.0
$$

The resulting equations are solved for pressure changes and flow rates. The solution is then advanced to higher time levels.

Figure (1) shows pulse-test terminology used in the rest of this paper. Define:

$$
\begin{array}{ll}
\Delta t_{c} & =\text { cycle period, } \min \\
R^{\prime} & =\text { pulse ratio } \\
R^{\prime} \Delta t_{c} & =\text { flow period, } \min \\
\left(1-R^{\prime}\right) \Delta t_{c} & =\text { shut-in period, min } \\
r & =\text { distance between active and observation wells, } \mathrm{ft}
\end{array}
$$


A New Technique to Predict Multilayered Reservoir Characteristics ....

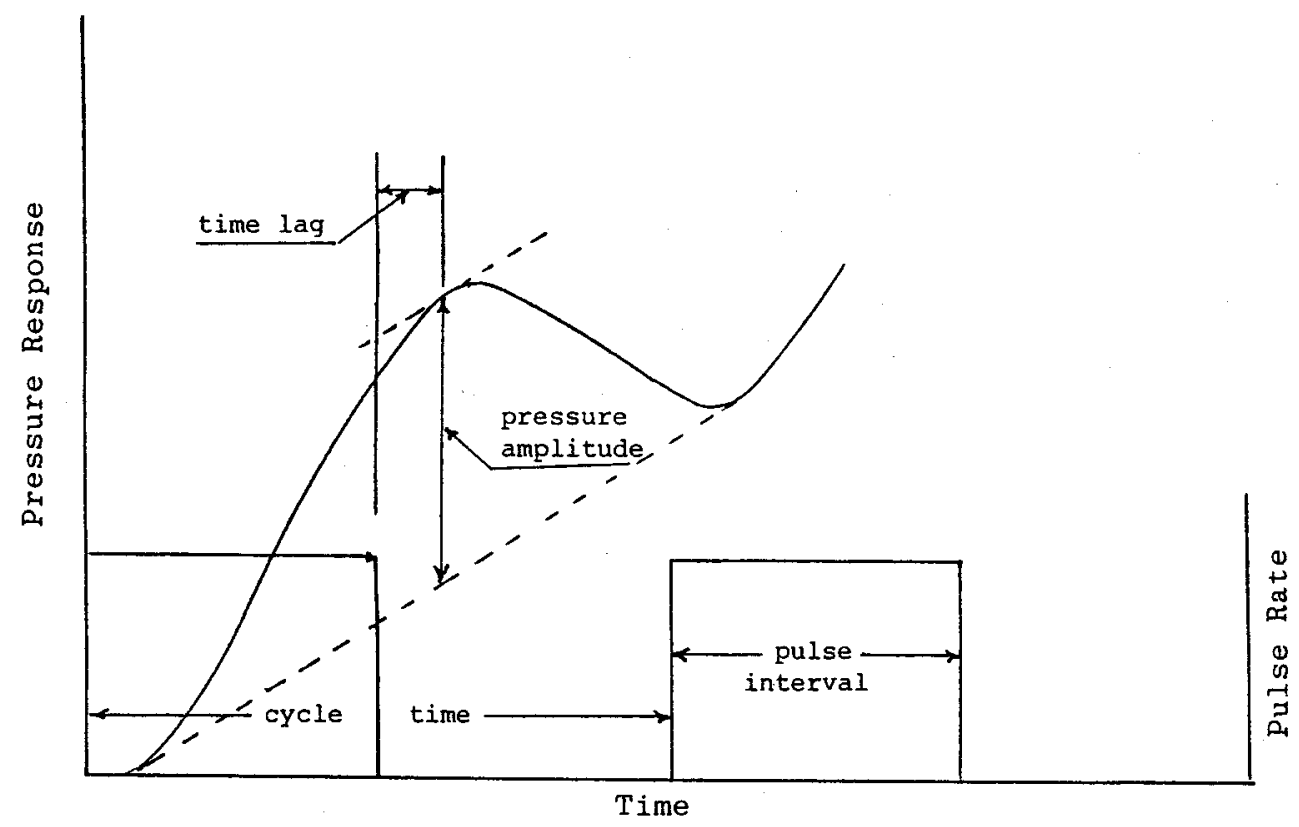

Fig. 1. Pulse-test terminology

Flow periods are considered, even pulses, $0,2,4,6,8 \ldots$ etc and shut-in periods odd pulses $1,3,5, \ldots$ etc. Any pulse $n$ lies between times $t_{n-1}$ and $t_{n}$ where

$$
\begin{array}{rlr}
t_{n-1} & =(n / 2) \Delta t_{c} & \text { for even pulses } \\
& =\left(\frac{n-1}{2}+R^{\prime}\right) \Delta t_{c} & \text { for odd pulses }
\end{array}
$$

and

$$
\begin{aligned}
t_{n} & =\left(n / 2+R^{\prime}\right) \Delta t_{c} & & \text { for even pulses } \\
& =\left(\frac{n+1}{2}\right) \Delta t_{c} & & \text { for odd pulses }
\end{aligned}
$$

Let $\mathbf{T}_{\mathbf{j}}$ is transmissibility of layer $\mathbf{j}$. Define:

$$
\Delta t_{c D j}=\frac{T_{j} \Delta t_{c}}{56900 \mathrm{~s}_{j} r^{2}{ }_{D} r^{2}{ }_{w r}} \quad j=1,2, \ldots . N
$$




$$
\begin{array}{ll}
r_{D}=r / r_{w r} & \\
P_{D j}=\frac{T_{j} \Delta p}{141.2 Q \beta_{0}} & j=1,2, \ldots N \\
P_{D r j}=\frac{T_{p} \Delta p}{7.06 Q \beta_{0}} & j=1,2, \ldots N \\
t_{D}=t / \Delta t_{c} & \\
t_{D i}=t_{i} / \Delta t_{c} & \\
f_{j}=\frac{q_{j}}{Q} & j=1,2, \ldots N
\end{array}
$$

Using the above set of definitions, dimensionless pressure response for layer $j$ is obtained from Equation (1) as:

$$
\begin{aligned}
P_{D r j}= & \frac{-1}{2}\left[\sum_{i=1}^{n}(-1)^{i} f_{j} \operatorname{Ei}\left(\frac{-r^{2}{ }_{D}}{\Delta t_{c D j}\left(t_{D}-t_{D i}\right.}\right)\right] \\
& +\sum_{i=1}^{n}(-1)^{i} \frac{q_{r j}}{Q} E i\left(\frac{-1}{\Delta t_{c D j}\left(t_{D}-t_{D i}\right.}\right) \quad j=1,2, \ldots N
\end{aligned}
$$

Although total flow rate from the pulser is constant during flow periods, the individual flow rates vary with time during flow periods and is constant $(=0)$ during shut-in periods. To take such variations into account, superposition technique in time is applied to obtain an expression for $\mathrm{P}_{\mathrm{Drj}}$ as: 
A New Technique to Predict Multilayered Reservoir Characteristics ....

$$
\begin{aligned}
P_{D r j}= & -\frac{1}{2}\left(\sum_{i=2 k}^{n} \sum_{m=1}^{M}\left(f_{j, i, m}-f_{j, i, m-1}\right) E i\left[\frac{-r_{D}^{2}}{\Delta t_{c D j}\left[t_{D n}-\left(t_{D i}+t_{D m-1}\right)\right]}\right]\right. \\
& +\sum_{i=2 k}^{n} \sum_{m=1}^{M} \frac{q_{r j}}{Q} E i\left(\frac{-1}{\Delta t_{c D j}\left[t_{D n}-\left(t_{D i}-t_{D m-1}\right)\right]}\right) \\
& -\sum_{i=2 k-1}^{n} f_{j i} E i\left[\frac{-r_{D}^{2}}{\Delta t_{c D j}\left(t_{D n}-t_{D i}\right.}\right] \\
& -\sum_{i=2 k-1}^{n} \frac{q_{r j}}{Q} E i\left[\frac{-1}{\Delta t_{c D j}\left(t_{D n}-t_{D i}\right.}\right] \quad j=1,2, \ldots N
\end{aligned}
$$

Similarly, Equation (2) is written in dimensionless form as:

$$
\begin{aligned}
& P_{D p j}=-\frac{1}{2}\left(\sum_{i=2 k}^{n} \sum_{m=1}^{M}\left(f_{j, i, m}-f_{j, i, m-1}\right) E i\left[\frac{1}{\Delta t_{c D j}\left[t_{D n}-\left(t_{D i}+t_{D m-1}\right)\right]}\right]\right. \\
& +\sum_{i=2 k}^{n} \sum_{m=1}^{M} \frac{q_{r j}}{Q} E i\left(\frac{-r_{D}^{2}}{\Delta t_{c D j}\left[t_{D n}-\left(t_{D i}-t_{D m-1}\right)\right]}\right) \\
& -\sum_{i=2 k-1}^{n} f_{j i} E i\left[\frac{-1}{\Delta t_{c D j}\left(t_{D n}-t_{D i}\right.}\right] \\
& -\sum_{i=2 k-1}^{n} \frac{q_{r j}}{Q} E i\left[\frac{-r_{D}^{2}}{\Delta t_{c D j}\left(t_{D n}-t_{D i}\right.}\right] \quad j=1,2, \ldots N
\end{aligned}
$$

In Equations (15) and (16), it is assumed cross flow $q_{r j}$ is constant during a particular pulse. It should be mentioned that Equations (1), (2), (3) and (4) are of general nature and can be applied in interference testing as well as in pulse testing. 


\section{RESULTS AND DISCUSSIONS}

For simplicity and convenience, one layer (say layer $\mathrm{j}, \mathrm{j}=1,2, .$. or $\mathrm{N}$ ) is picked up to present the layer of interest. The properties of layer $j$ are correlated to those of the system by factors $A$ and $B$ as follows:

$$
\begin{array}{lll}
\mathrm{T}_{\mathrm{j}}=\mathrm{A} \mathrm{T}_{\mathrm{s}}, & 0.0<\mathrm{A}<1, & \mathrm{j}=1,2, \ldots \mathrm{N} \\
\mathrm{S}_{\mathrm{j}}=\mathrm{B} \mathrm{S}_{\mathrm{s}}, & 0.0<\mathrm{B}<1, & \mathrm{j}=1,2, \ldots \mathrm{N}
\end{array}
$$

where $T_{S}$ and $S_{S}$ are total transmissibility and storage respectively and given as:

$$
\mathrm{T}_{\mathrm{s}}=\sum_{\mathrm{j}=1}^{\mathrm{N}} \mathrm{T}_{\mathrm{j}}=\mathrm{K}_{\mathrm{av}} \mathrm{h}_{\mathrm{t}} \mu_{\mathrm{o}} \text { and } \mathrm{S}_{\mathrm{s}}=\sum_{\mathrm{j}=1}^{\mathrm{N}} \mathrm{S}_{\mathrm{j}}=\phi_{\mathrm{av}} \mathrm{h}_{\mathrm{t}} \mathrm{C}_{\mathrm{t}}
$$

for special cases of $A=1$ and/or $B=1$, the system's consist of just one layer. The calculations were performed using the following parameters unless otherwise specified:

$$
\begin{aligned}
T_{j} & =100 \mathrm{md} . \mathrm{ft} / \mathrm{cp}, \quad r=1000 \mathrm{ft} \\
\mathrm{S}_{\mathrm{j}} & =0.00002 \mathrm{ft} / \mathrm{psi}
\end{aligned}
$$

The use of Ei solution as an interpretive model for multilayer systems yields apparent properties, which are different from true values of individual layers. In this study the apparent transmissibility $\left(\mathrm{T}_{\mathrm{a}}\right)$ and storage $\left(\mathrm{S}_{\mathrm{a}}\right)$ are graphically correlated to those of individual layers. The effects of different parameters are also discussed. The results are presented in $\log -\log$, semi-log and Cartesian plots.

\section{Fractional Production Rates}

Figure (2) presents the fractional production rate from layer $\mathrm{j}$ versus $\Delta \mathrm{t}_{\mathrm{cD}}$ for different values of transmissibility fraction of that layer. The figure indicates that the fractional production rate from layer $j$ is not proportional to its transmissibility fraction. Thus assuming a constant fractional flow rate (equals to the layer's transmissibility fraction) as suggested by Woods [4] may lead to erroneous results. 
For example, for a reservoir having $T=100 \mathrm{md} . \mathrm{ft} / \mathrm{cp}$, storage $=0.0002 \mathrm{ft} / \mathrm{psi}, \mathrm{r}=$ $1000 \mathrm{ft}$ and cycle time $\left(\Delta_{\mathrm{tc}}\right)=10 \mathrm{hrs}, \Delta \mathrm{t}_{\mathrm{CD}}=8.8 \times 10^{-4}$. Figure (2) shows that, for this reservoir with layer $j$ of $T_{j} / T_{s}=0.1, f_{j}=0.13$ with $30 \%$ higher than the value suggested by. Woods [4]. The figure also indicates that $f_{j}$ changes with dimensionless cycle time. As the time increases, the fractional production rate reaches an asymptotic value equals to the layer transmissibility fraction.

The calculations indicate that, from practical point of view, variations in storage have minor effects on fractional production rates. Figure (2) can be used in conjunction of a flowmeter survey data to estimate transmissibility fractions of different layers.

Figure (3) presents crossflow between layer $j$ and the rest of the layers for different values of skin $\left(S_{j}\right.$ and $\left.S_{r}\right)$. The figure indicates that wellbore damage alters the fractional flow through the layers and consequently the crossflow between layers. Such alteration affect both apparent storage and transmissibility.

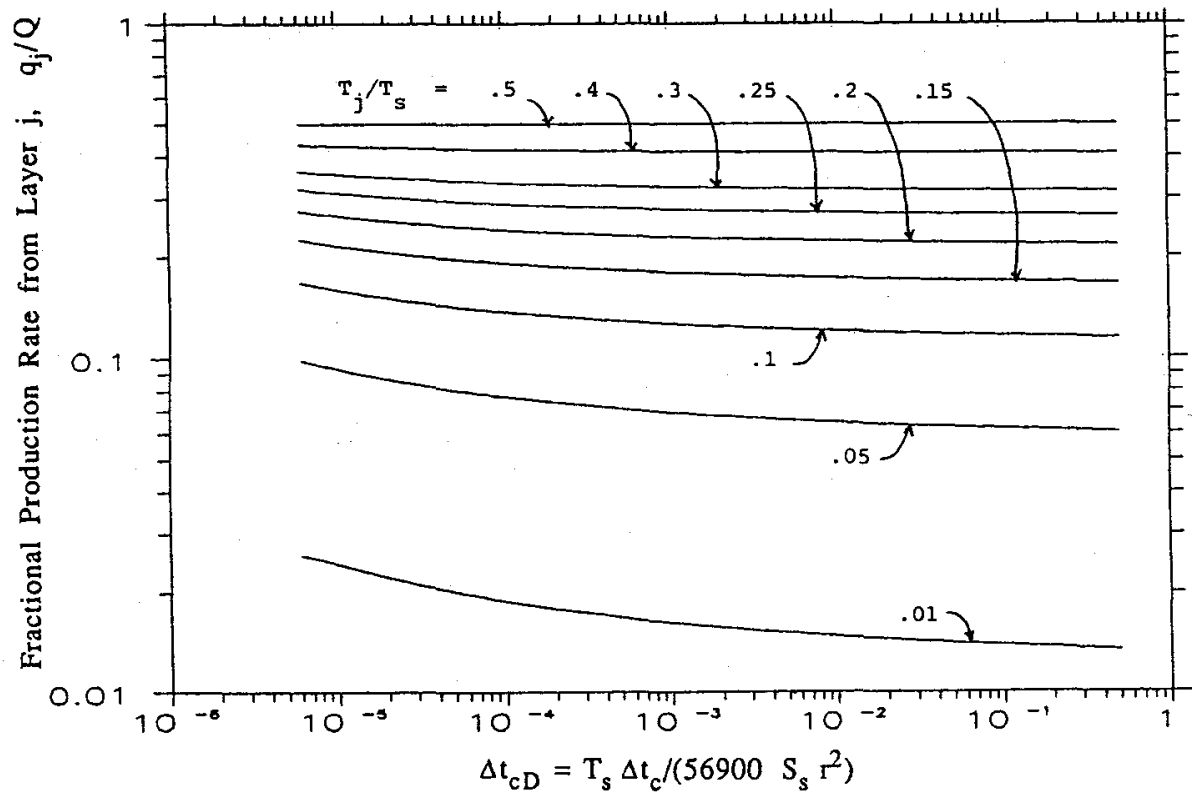

Fig. 2. Effect of pulse length on fractional production rate for different values of transmissibility fractions 


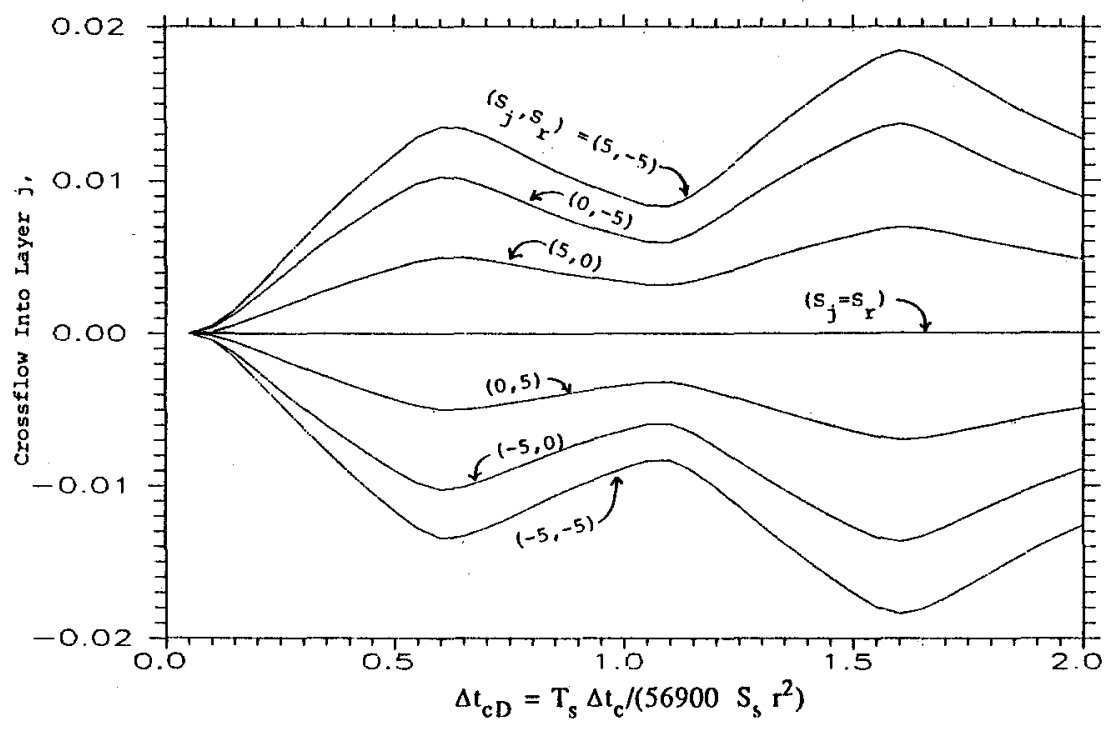

Fig. 3. Effect of wellbore damage at the pulser on the crossflow between layers at the observer

\section{Effect of Wellbore Storage}

Figure (4) presents the effect of wellbore storage on fractional production rate or total production rates versus cycle dimensionless time for $T_{j} / T_{s}=0.1$. The effect of wellbore increases as the dimensionless wellbore storage coefficient increases. The ideal situation is to have a downhole shutting device to eliminate such effect. As the time increases the effect of wellbore storage decreases. Such effect becomes nil for $\Delta t_{c D} \geq 1$. Fig. (5) presents the case of $T_{j} / T_{s}=0.3$. Comparing Figs. (4) and (5) indicates that transmissibility fractions affects $\mathrm{C}_{\mathrm{ft}}$ factors at high wellbore storage coefficients. This can be explained in the light of understanding that as $T_{j} / T_{s}$ value increases, the fractional production rate of the layer increases to substitute the production from the wellbore and consequently the effect of wellbore storage decreases and vice versa. This study was extended to investigate the effect of $S_{j} / S_{s}$. The results (not shown) indicated that such effects are negligible. 
A New Technique to Predict Multilayered Reservoir Characteristics ....

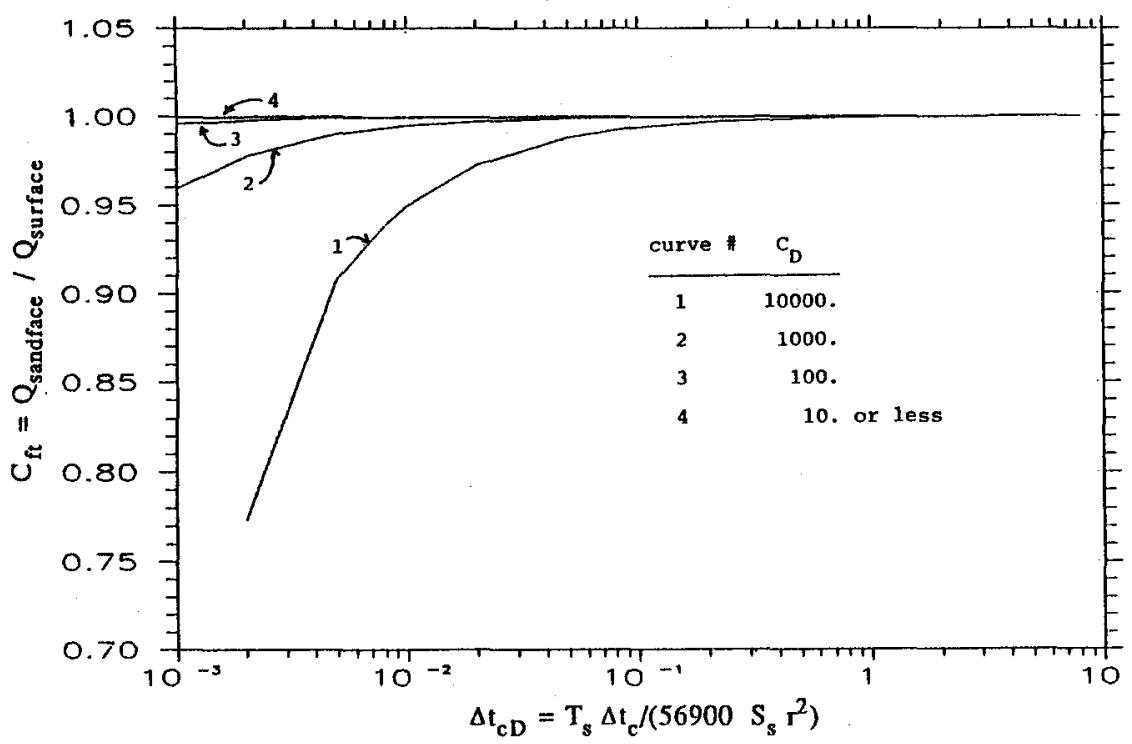

Fig. 4. Effect of wellbore storage on fractional production rate for transmissibility fraction $=0.1$

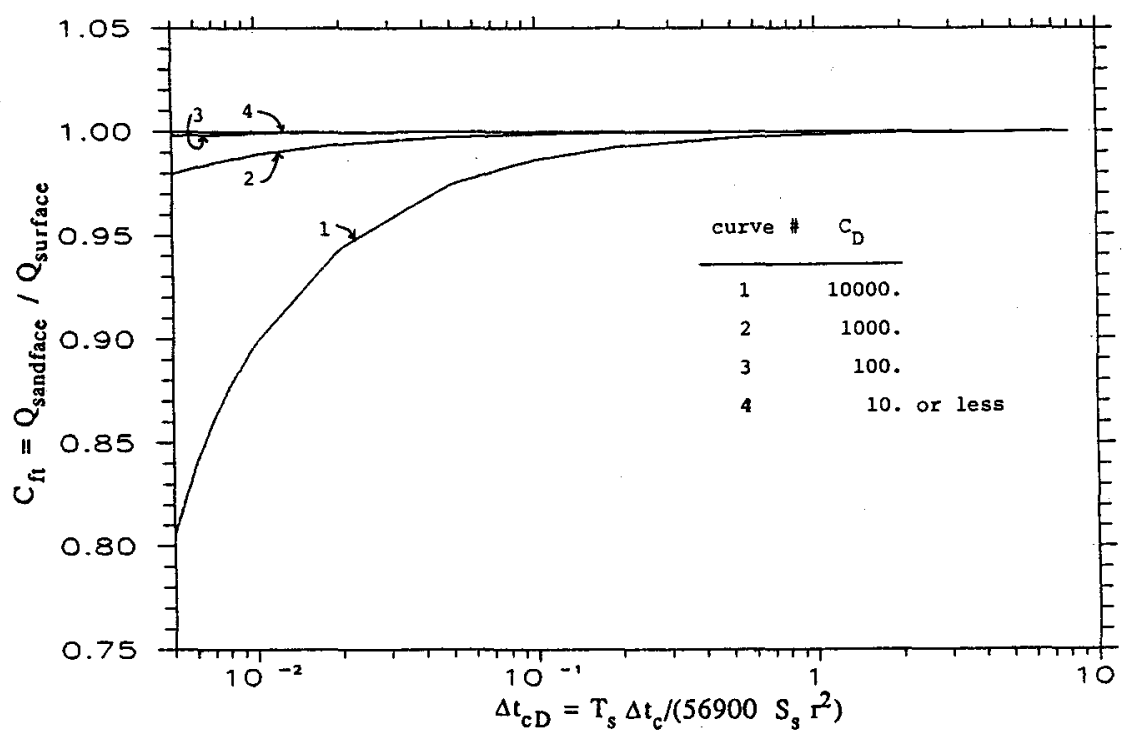

Fig. 5. Effect of wellbore storage on fractional production rate for transmissibility fraction $=\mathbf{0 . 3}$ 


\section{Effect of Wellbore Damage}

Wellbore damage or stimulation may alter the fractional production rates of different layers of multilayered systems and the pressure at the pulsing well may be consequently changed. Thus apparent transmissibility and storage of the system may be changed due to wellbore damage and/or stimulation. The multilayer system is some how complicated as some of the layers may be damaged and the others may be improved (with different levels of damage and improvement). For simplicity, the system of layers is represented by a layer $j$ (layer of interest) with skin $S_{j}(j=1,2, \ldots$ $N$ ) in addition to the rest of the layers with average skin $S_{r}$. To study the effect of wellbore damage on apparent transmissibility $\left(\mathrm{T}_{\mathrm{a}}\right)$ and storage $\left(\mathrm{S}_{\mathrm{a}}\right)$, the calculations were carried out using -5 to 20 values for both $S_{j}$ and $S_{r}$. The results are presented in Figures (6 to 9). Figure (6) present the change of $S_{a}\left(\Delta S_{a} / S_{S}\right)$ versus $\left(S_{j} / S_{s}\right)$ for different values of $S_{r}$ with $T_{j} / T_{s}=0.1$. As the skin of layer $j$ increases, the change

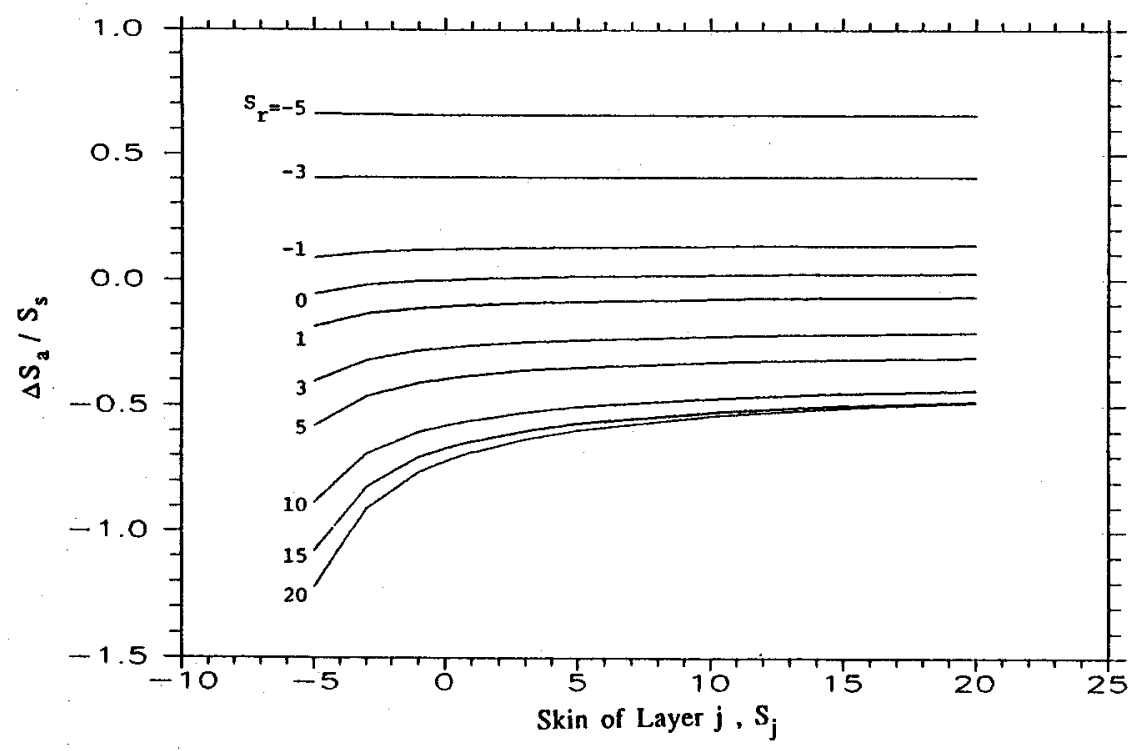

Fig. 6. Effect of wellbore damage on apparent storage for transmissibility fraction $=0.1$ 
A New Technique to Predict Multilayered Reservoir Characteristics ....

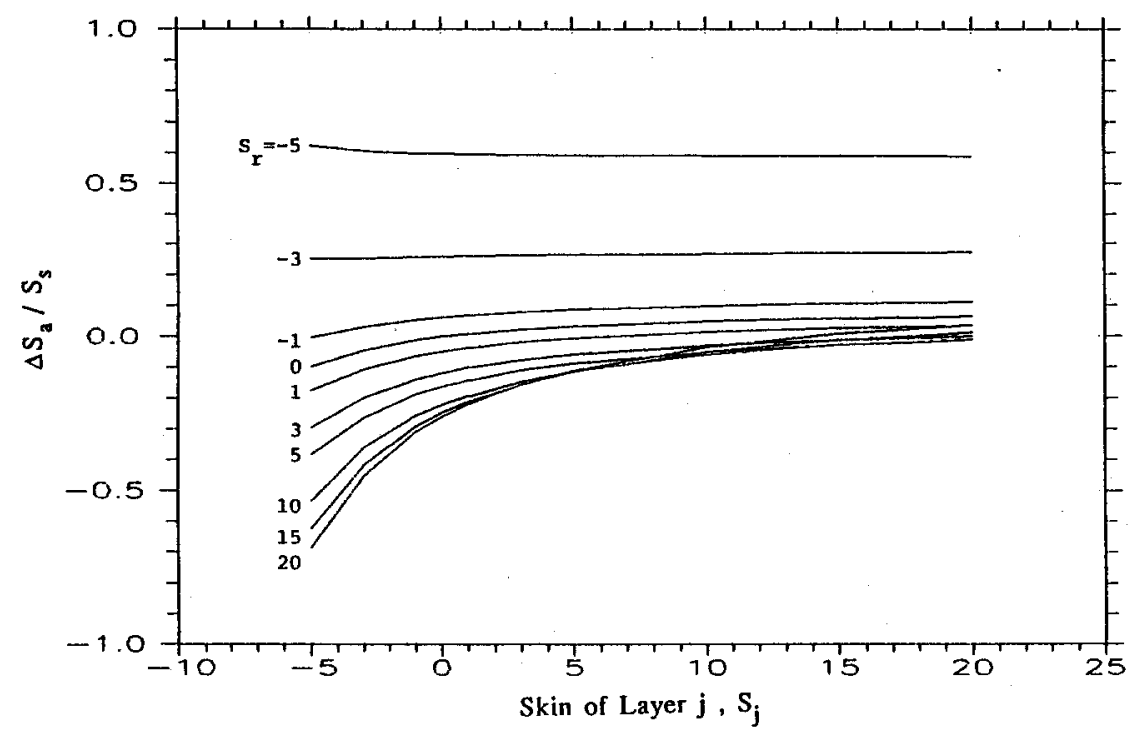

Fig. 7. Effect of wellbore damage on apparent storage for transmissibility fraction $=0.3$

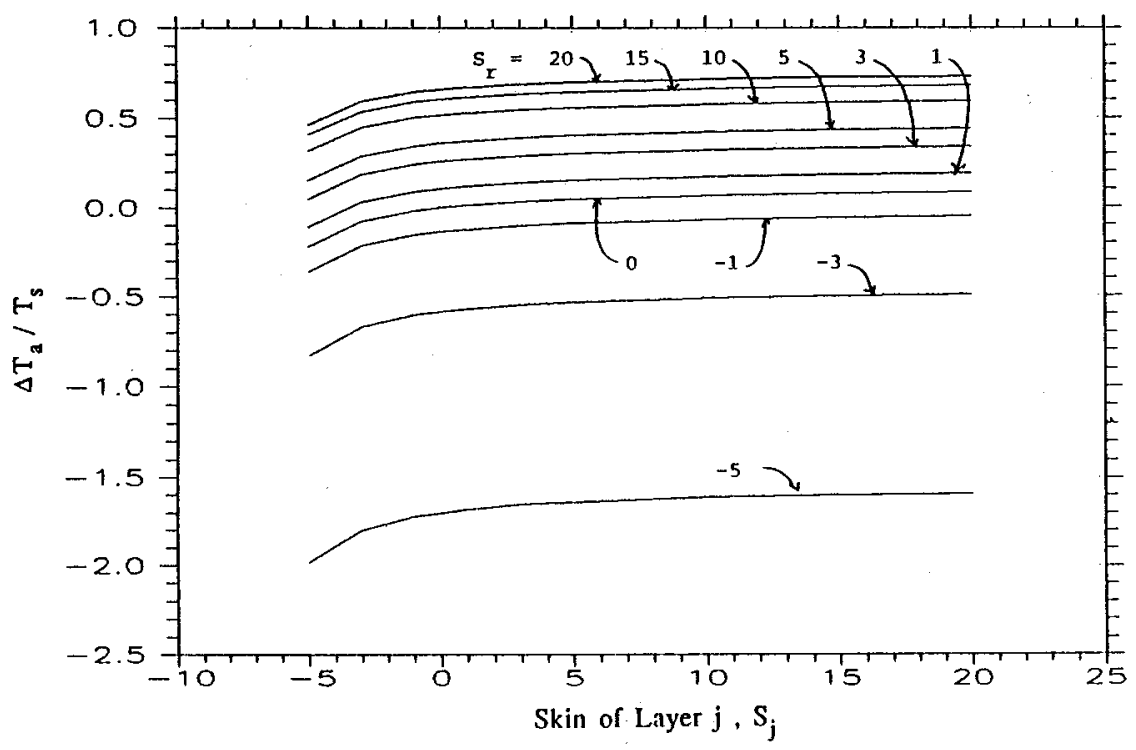

Fig. 8. Effect of wellbore damage on apparent transmissibility for transmissibility fraction $=0.1$ 


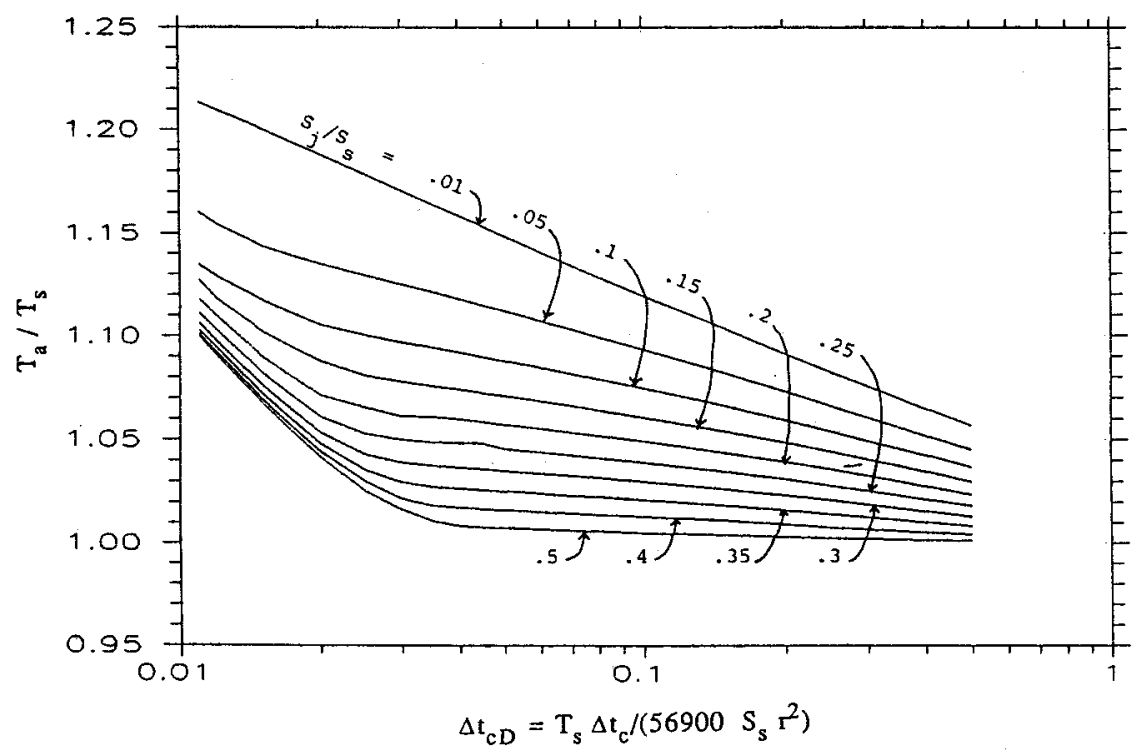

Fig. 9. Effect of pulse length on apparent transmissibility for different values of storage

in $S_{a}$ decreases for $S_{r} \geq 0$. For $S_{r}<0$, the change in $S_{a}$ becomes constant. Figure (7) presents the same case presented in Figure (3) for $T_{j} / T_{s}=0.3$. The curves presented in the figure have the same characteristics as those presented in Figure (3). Comparing the two Figures (6) and (7) indicates that $\left(\Delta S_{a} / S_{s}\right)$ is affected by the change in $T_{j} / T_{s}$.

Figure (8) presents the effects of wellbore damage on apparent transmissibility $\left(T_{a}\right)$ for transmissibility fraction $=0.1$. As $S_{r}$ and/or $S_{j}$ increases, change in apparent transmissibility decreases. The calculations indicate that as the transmissibility fraction increases the change in apparent transmissibility decreases especially for negative skin factors. The calculations indicated that wellbore damage at the pulser has no effect on pressure amplitude at the observer.

\section{Effect of Pulse Interval}

The relationship between apparent to total transmissibility ratio $\left(\mathrm{T}_{\mathrm{a}} / \mathrm{T}_{\mathrm{s}}\right)$ and dimensionless cycle time is presented in Figure (9) for different values of the ratio $\left[\left(1 / S_{j}\right) / \Sigma\left(1 / S_{j}\right)\right]$. As the values of $T_{a} / T_{s}$ and $S_{a} / S_{s}$ become closer to unity as better 
estimation of reservoir transmissibility and storage are obtained using pulse testing data. Figure (9) indicates that as the pulse interval increases as the ratio $\left(T_{a} / T_{s}\right)$ converges to unity. Such convergence is fast during early time of the pulse interval especially for the cases of low contrast in storage. This means that a better estimation is obtained using long cycle interval. However, as pulse interval increases, real heterogeneities from distant locations may affect the results. It can be noted from Figure (9) that $T_{a} / T_{s}$ is always higher than 1 for all values of $S_{j} / S_{s}$. This means that pulse testing data always give values for apparent transmissibility higher than the true values calculated from individual layer transmissibilities.

Figure (10) presents apparent to total storage ratio $\left(S_{a} / S_{s}\right)$ versus dimensionless cycle time $\left(\Delta t_{c D}\right)$ for different values of individual transmissibility fractions. As the value of $\mathrm{S}_{\mathrm{a}} / \mathrm{S}_{\mathrm{s}}$ becomes closer to unity as a better estimation of reservoir transmissibility is obtained using pulse testing data. Figure (10) indicates that as the pulse interval increases as the ratio $\mathrm{S}_{\mathrm{a}} / \mathrm{S}_{\mathrm{s}}$ becomes slowly closer to unity and consequently a better estimation for reservoir storage is obtained with longer pulse intervals.

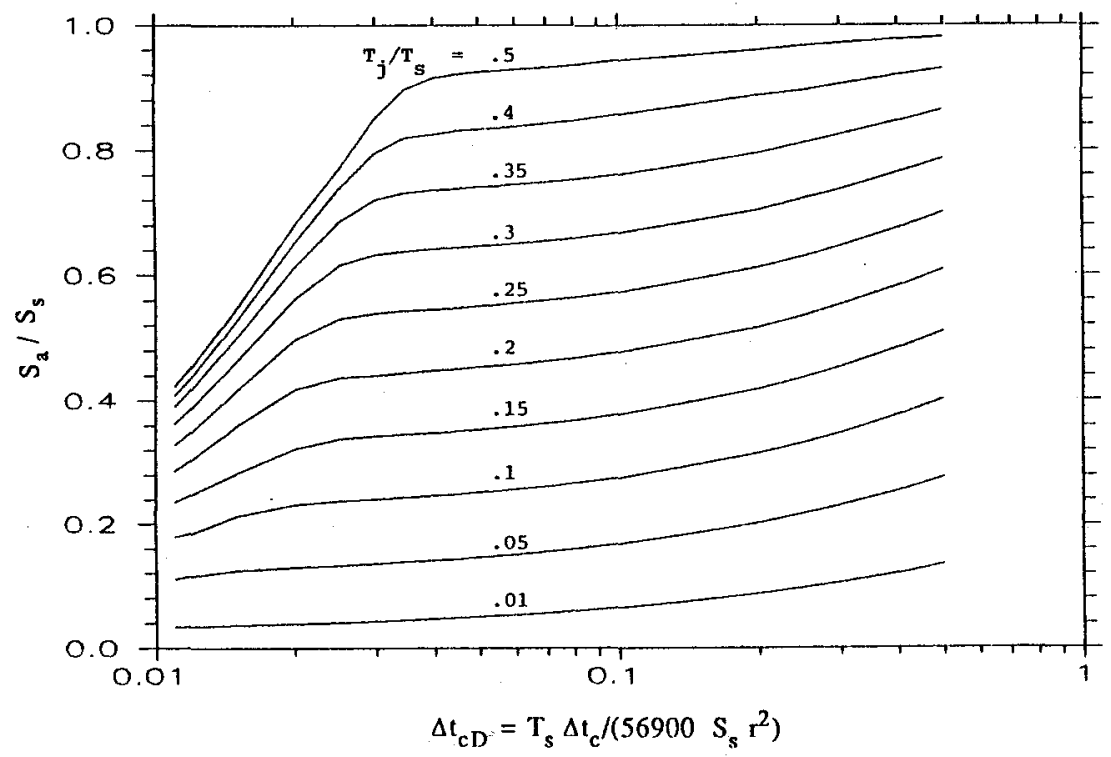

Fig. 10. Effect of pulse length on apparent storage for different values of transmissibilities 
Also, Figure (10) indicates that $S_{a} / S_{s}$ is always less than unity for all values of $\mathrm{T}_{\mathrm{j}} / \mathrm{T}_{\mathrm{s}}$. Thus pulse testing data gives always lower estimation for $\mathrm{S}_{\mathrm{a}}$ than the true values obtained from individual layer storativities.

Figures (9) and (10) show that as the contrast in reservoir properties increases less accurate estimation of apparent reservoir characteristics are obtained using pulse testing data and vice versa. The two figures indicate that during early time of the pulse $\left(t_{c D} \leq 0.03\right)$, for low contrast in reservoir storage and transmissibility, both apparent storage and transmissibility converge faster to a better estimation for both of them.

\section{Relationship Between Apparent and True Properties}

Figure (11 $a \& b)$ presents the relationship between $\left(\mathrm{S}_{\mathrm{a}} / \mathrm{S}_{\mathrm{S}}\right)$ ratio versus diffusivity ratio for different values of transmissibility fractions. As the transmissibility fraction increases, $\mathrm{S}_{\mathrm{a}} / \mathrm{S}_{\mathrm{s}}$ increases and approaches unity at transmissibility fraction equal to 1 . The figure also indicates that; as the contrast in reservoir properties increases, the difference between apparent and total storage increases; $\mathrm{S}_{\mathrm{a}} / \mathrm{S}_{\mathrm{s}}$ ratio is a strong function of individual layer properties; and the apparent storage is always less or equal to the total storage. Figure $(12 \mathrm{a} \& \mathrm{~b})$ presents the relationship between $\left(T_{a} / T_{s}\right)$ ratio versus diffusivity ratio for different values of transmissibility fractions. As the transmissibility fraction increases, $\left(T_{a} / T_{s}\right)$ ratio decreases and approaches a unity at transmissibility fraction equal to 1. Figure (12) shows the difference between apparent and total transmissibility increases as the contrast in transmissibility fraction increases; and the apparent transmissibility is always higher than or equal to the total transmissibility. It should be mentioned that Figures (11) and (12) are based on $\Delta t_{c D}=0.5$. If the actual $\Delta t_{c D}$ is different, $T_{a} / T_{s}$ and $S_{a} / S_{s}$ should be corrected using Figures (9) and (10) respectively.

\section{Applications}

Pulse testing procedure for multizone systems may be categorized as follows:

A. Isolated zones in both responding and pulsing wells

When a particular zone can be separated by packers or other means, the pulse test data for such zone can be analyzed to determine its characteristics (transmissibility and storage). One of the methods reported in References [11], [12], or [17] can be used for this purpose. 
A New Technique to Predict Multilayered Reservoir Characteristics

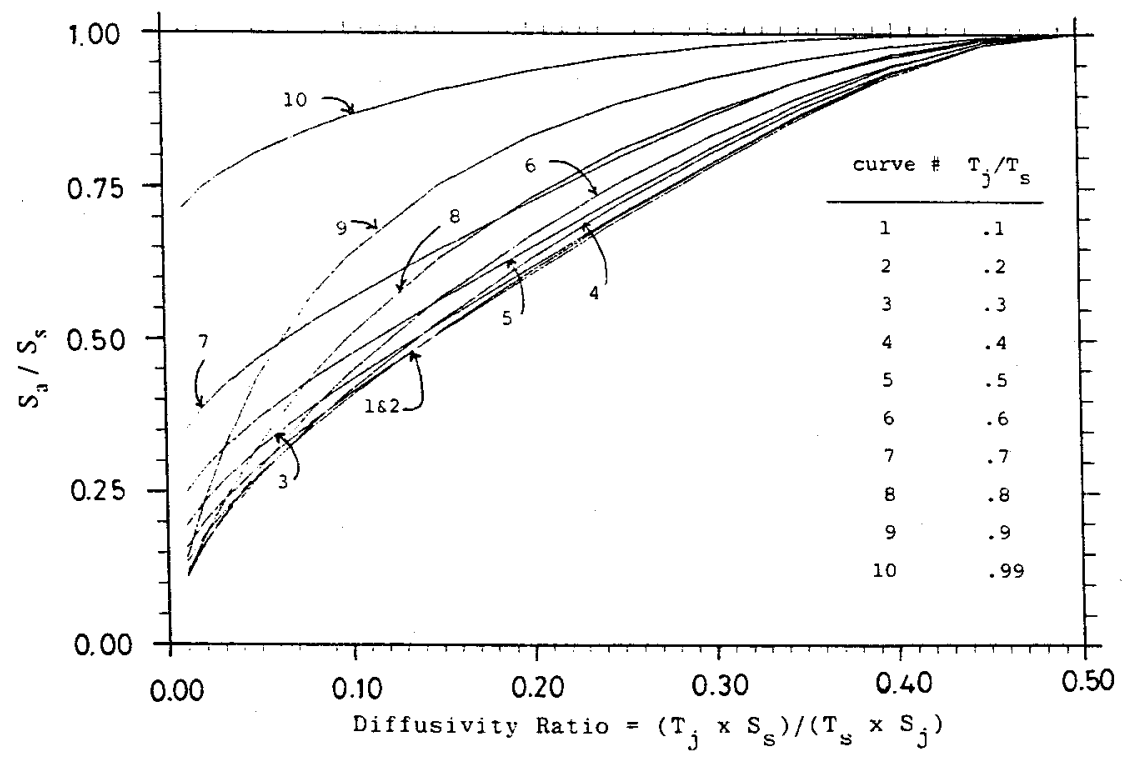

Fig. 11a. Relationship between apparent storage and diffusivity for different values of transmissibility fractions

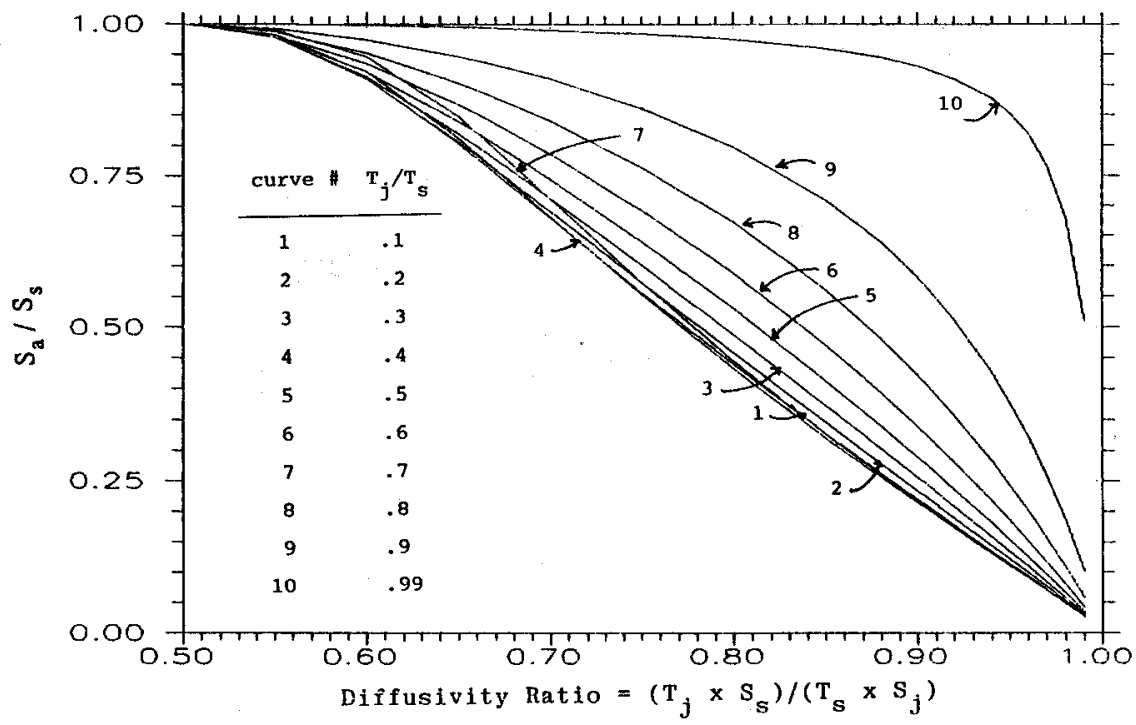

Fig. 11b. Relationship between apparent storage and diffusivity for different values of transmissibility fractions 
M.E. Osman and S.A. Mohammed

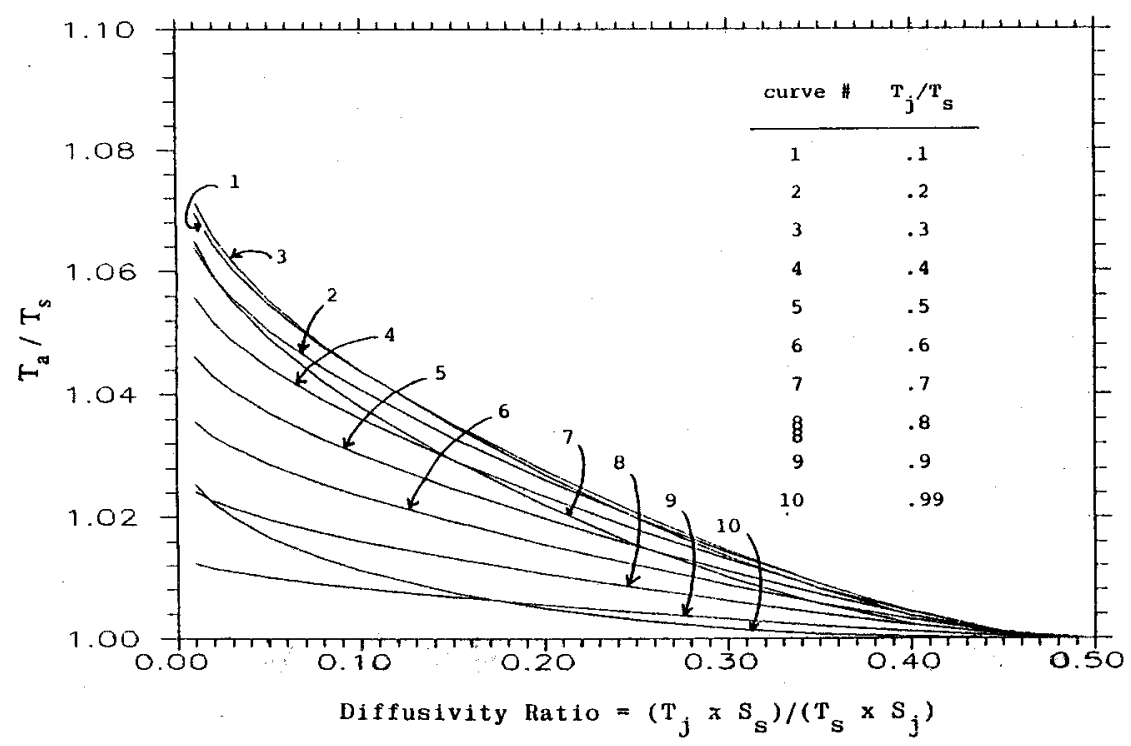

Fig. 12a. Relationship between apparent transmissibility and diffusivity for different values of transmissibility fractions

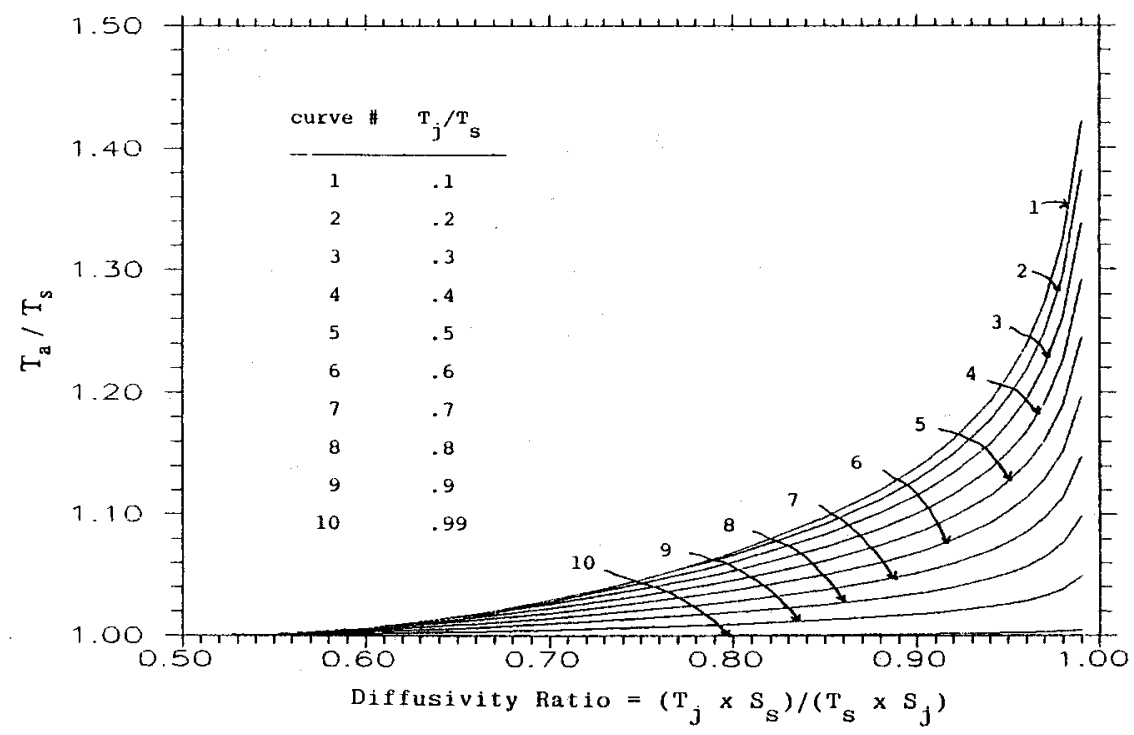

Fig. 12b. Relationship between apparent transmissibility and diffusivity for different values of transmissibility fractions 


\section{B. Isolated zones in pulser only}

This presents the case of layers commingled at the observer only. For such case, production rates from different zones are known. The following procedure is suggested:

1. Measure production rate from different layers at the pulser.

2. Measure bottom hole pressure of the observation well versus time.

3. Correct the pressure amplitude and time lag for the cross flow between the layer of interest and the other layers. The model developed for this study may be used for this purpose.

4. Estimate layer characteristics as done in case A (isolated zones in both pulser and observer).

5. Repeat steps $\mathbf{3}$ and $\mathbf{4}$ for different layers.

C. Isolated zones in responding well only

This represents the case of layers commingled at the pulser only. Such reservoirs can be pulse tested using the following procedure.

1. Run flowmeter survey in the pulsing well to estimate production rate from each layer.

2. Record pressure-time data of a pulse test opposite each of the isolated zones.

3. Estimate reservoir characteristics as done in the case of isolated zones in both responding and pulsing well (case A).

D. Zones not isolated in both responding and pulsing wells

This presents the case where the layers are commingled in both wells. Such reservoirs can be pulse tested using the following procedure.

1. Run a flowmeter survey in the pulsing well to estimate production rate from each zone.

2. Record pressure-time data in the responding well.

3. Estimate to reservoir characteristics as done in the example presented later.

\section{Interpretation Procedure}

For the above mentioned categories, the following steps should be performed (whenever necessary):

A- Use single well test data for both wells (the pulser and observer) to estimate total transmissibility of the reservoir from:

$$
\mathrm{T}_{\mathrm{s}}=\sqrt{\left(\mathrm{T}_{\mathrm{s}}\right)_{\text {pulser }} \cdot\left(\mathrm{T}_{\mathrm{s}}\right)_{\text {observer }}}
$$


Also single-well test data are used to determine wellbore conditions. Such as wellbore storage and damage.

B- Pulse test data are analyzed (as normally done for single layer system using one of the published methods) to estimate apparent transmissibility and storage. Correct production rate for wellbore storage effects using proper chart such as Figure (4) before analyzing well test data.

C- Correct apparent storage and transmissibility for wellbore damage using proper charts such as Figures (6) to (8).

D- Use flowmeter data in conjunction with fractional production rate plot to estimate transmissibility fraction for each layer.

E- Use Figure (12) to estimate storage fraction $\left(\mathrm{S}_{\mathrm{i}} / \mathrm{S}_{\mathrm{S}}\right)$ and consequently determine $\left(\mathrm{S}_{\mathrm{a}} / \mathrm{S}_{\mathrm{S}}\right)$ from Figure (11). Thus $\mathrm{S}_{\mathrm{r}}$ is estimated. Repeat steps $\mathrm{C}, \mathrm{D}$ and $\mathrm{E}(\mathrm{N}-1)$ times. The Nth layer properties are obtained from:

$$
S_{s}=S_{N}-\sum_{j=1}^{N-1} S_{j}
$$

F- Calculate $\Delta t_{c D}=\frac{T_{s} \Delta t}{56900 S_{s} r^{2}}$

If the calculated value is equal to 0.5 , correct $\mathrm{T}_{\mathrm{a}} / \mathrm{T}_{\mathrm{S}}$ and $\mathrm{S}_{\mathrm{a}} / \mathrm{S}_{\mathrm{S}}$ using Figures (9) and (10) and repeats the calculations.

\section{Example}

This example shows how to interpret test data (single wells in addition to pulse test data) for a three-layer reservoir to obtain transmissibility and storage of different layers. The tests were performed on wells 1 and 2 which $1000 \mathrm{ft}$ distant from each other. Production rate during pulse test was 1000 STB/day. Test data are reported in Table (1). The calculations are performed as follows: 
A New Technique to Predict Multilayered Reservoir Characteristics ....

Table 1. Three-Layer Reservoir Test Data and Results

i) Flow meter and single well test data for the pulser

\begin{tabular}{|c|c|c|}
\hline \multirow{2}{*}{ Layer \# } & \multicolumn{2}{|c|}{ Well \# 1 Data } \\
\cline { 2 - 3 } & Skin & $\mathrm{f}_{\mathfrak{j}}$ \\
\hline 1 & 5 & 0.1 \\
2 & 0 & 0.3 \\
3 & 0 & 0.6 \\
\hline $\mathrm{T}_{\mathrm{s}}$ & \multicolumn{2}{|c|}{$45000 \mathrm{md} . \mathrm{ft} / \mathrm{cp}$} \\
\hline
\end{tabular}

ii) Single well test data for the observer:

$$
\mathrm{T}_{\mathrm{S}}=60,000 \mathrm{md} . \mathrm{ft} / \mathrm{cp}
$$

No data available for the skin

iii) Pulse test data:

$$
\begin{aligned}
& \mathrm{T}_{\mathrm{a}}=55,000 \\
& \mathrm{~S}_{\mathrm{a}}=4.6 \times 10-5
\end{aligned}
$$

Distance between well $\mathrm{l}$ and $2=1000 \mathrm{ft}$ Cycle time $=2$ hrs.

iv) Results:

\begin{tabular}{|c|c|c|}
\hline Layer \# & $\mathrm{T}_{\mathrm{j}^{\prime} \mathrm{md} . \mathrm{ft}}$ & $\mathrm{S}_{\mathrm{j}}$, ft/psi \\
\hline 1 & $6.24 \times 10^{3}$ & $1.69 \times 10^{5}$ \\
2 & $16.62 \times 10^{3}$ & $6.48 \times 10^{5}$ \\
3 & $29.10 \times 10^{3}$ & $12.83 \times 10^{5}$ \\
\hline Total & $51.96 \times 10^{3}$ & $21 \times 10^{5}$ \\
\hline
\end{tabular}

A- Total transmissibility $\left(T_{S}\right)=(45000 \times 60000)^{1 / 2}=51.96 \times 10^{3} \mathrm{md} . \mathrm{ft} / \mathrm{cp}$

B- $\mathrm{T}_{\mathrm{a}}=55000 \mathrm{md} . \mathrm{ft} / \mathrm{cp}$. and $\mathrm{S}_{\mathrm{a}}=4.62 \times 10^{-5} \mathrm{ft} / \mathrm{psi}$ (from the analysis of pulse test data) 
C- using skin factors $S_{1}=5$ and $S_{r}=0$, from Figure (6) $\frac{\Delta S_{a}}{S_{s}}=0.02$ (to be used later) from Figure (8) $\frac{\Delta \mathrm{T}_{\mathrm{a}}}{\mathrm{T}_{\mathrm{s}}}=0.05$ thus $\frac{\mathrm{T}_{\mathrm{a}}}{\mathrm{T}_{\mathrm{s}}}=\frac{55000}{51.96 \times 10^{3}}+\frac{\Delta \mathrm{T}_{\mathrm{a}}}{\mathrm{T}_{\mathrm{s}}}=1.11$

D- from Figure (2), at $\Delta t_{c D}=0.5$,

for $f_{1}=0.1, \frac{T_{1}}{T_{S}}=0.12$

for $f_{2}=0.3, \frac{T_{2}}{T_{s}}=0.32$

for $f_{3}=0.6, \frac{T_{2}}{T_{s}}=0.56$

with $\mathrm{T}_{\mathrm{S}}=51.96 \mathrm{md} \mathrm{ft} / \mathrm{cp}$, individual layer transmissibilities are obtained as:

$\mathrm{T}_{1}=6.24 \times 10^{3} \mathrm{md} . \mathrm{ft} / \mathrm{cp}$

$\mathrm{T}_{2}=16.62 \times 10^{3} \mathrm{md} . \mathrm{ft} / \mathrm{cp}$ and

$\mathrm{T}_{3}=29.1 \times 10^{3} \mathrm{md} . \mathrm{ft} / \mathrm{cp}$

E- using Figure (12), with $\mathrm{T}_{\mathrm{a}} / \mathrm{T}_{\mathrm{s}}=1.11$ and $\mathrm{T}_{\mathrm{l}} / \mathrm{T}_{\mathrm{s}}=0.12, \frac{\mathrm{S}_{1}}{\mathrm{~S}_{\mathrm{s}}}=0.08$

From Figure (11), $\frac{S_{a}}{S_{s}}=0.2$. Corrected $\frac{S_{a}}{S_{s}}=0.22$

$S_{s}=\frac{S_{a}}{0.22}=4.62 \times 10^{-5} / 0.22=21 \times 10^{-5} \mathrm{ft} / \mathrm{psi}$

Thus $\quad \mathrm{S}_{1}=1.69 \times 10^{-5} \mathrm{ft} / \mathrm{psi}$

Similarly, $S_{2}=6.48 \times 10^{-5} \mathrm{ft} / \mathrm{psi}$ and

$$
\mathrm{S}_{3}=12.83 \times 10^{-5} \mathrm{ft} / \mathrm{psi}
$$


A New Technique to Predict Multilayered Reservoir Characteristics ....

F- $\Delta \mathrm{t}_{\mathrm{CD}}=\frac{51.96 \times 10^{3} \times(2 \times 60)}{56900 \times 21 \times 10^{-5}(1000)^{2}}=0.52$

which is close to 0.5 .

The results are recorded in Table (1) for convenience.

It should be kept in mind that summation of transmissibility fractions or storage fractions equal to unity. If it differs from one, readings from Figure (2) or Figures (11) and (12) should be normalized.

\section{CONCLUSIONS AND RECOMMENDATIONS}

In this study, a new technique was developed to handle pulse testing data for multilayered reservoirs, The technique uses the data of single well tests, flowmeter surveys and pulse tests to determine properties (transmissibility and storage) of individual layers. The technique takes into account wellbore conditions and pulse intervals. The following conclusions and recommendations are withdrawn from this study;

1 apparent transmissibility is always greater than or equal to the actual transmissibility of the reservoir.

2. Apparent storage is always less than or equals to the actual storage of the reservoir.

3. For short cycle intervals, the fractional production rate from a particular layer is not proportional to its transmissibility fraction. However, the effect of storage on fractional production rate is negligible.

4. Wellbore damage at the pulser affects both apparent transmissibility and storage of the reservoir. Such effect on pressure amplitude at the observer is negligible. It is recommended to correct the apparent transmissibility and storage of the reservoirs using proper charts presented in this study.

5. As the contrast in reservoir properties increases less accurate estimation of apparent reservoir characteristics are obtained using pulse testing data and vice versa.

6. As the transmissibility fraction increases, $\mathrm{S}_{\mathrm{a}} / \mathrm{S}_{\mathrm{S}}$ increases and approaches unity at transmissibility fraction equal to 1 . 
7. As the storage fraction increases, $T_{a} / T_{s}$ decreases and approaches unity at storage fraction equal 1.

\section{REFERENCES}

1. Johnson, C.R., Greenkorn, R.A. and Wood, E.G., 1966. Pulse Testing: A New Method for Describing Reservoir Flow Proper Properties Between Wells, Trans., AIME, Vol. 237, pp.1599-1604.

2. Vela, S. and McKinley, R.M., 1970. How Areal Heterogeneties Affect Pulse Testing Results, Trans., AIME, Vol. 249, pp. 181-191.

3. Prats, M. and Scott, J.B., June 1975. Effect of Wellbore Storage on PulseTest Pressure Response, JPT, pp. 707-709.

4. Woods, E.C., Sept. 1970. Pulse-Test Response of a Two-Zone Reservoir, Soc. Pet. Eng. J., Trans., AIME, Vol. 249, pp. 245-256.

5. Brigham, W.E., May 1970. Planning and Analysis of Pulse Tests, JPT, Trans., AIME, Vol. 249, pp. 618-624.

6. Kamal, M. and Brigham, W.E., Oct. 1975. Pulse-Testing Response for Unequal pulse and shut-in periods, Soc. Pet. Eng. J., pp. 399-410.

7. Matthies, E.P., March 1964. Practical Application of Interfering Tests, JPT, pp. 249-52.

8. McKinley, R.M., Vela, S. and Carlton, L.A., March 1968. A Field Application of Pulse-Testing for Detailed Reservoir Description, JPT, Trans., AIME, Vol. 243, pp. 313-21.

9. Ramey, H.J.Jr., Oct. 1975. Interface Analysis for Anistropic Formations-A Case History, JPT, pp. 1290-98.

10. Pierce, A.E., Aug. 1977. Case History: Waterflood performance predicted by pulse Testing, JPT, pp. $914-918$. 
A New Technique to Predict Multilayered Reservoir Characteristics ....

11. Al-Khalifah, A.A., Al-Hashim, H.S., Al-Marhoun, M.A. and Menouar, H.K., Sept. 22-25, 1985. Revised Pulse-Testing Correation Charts, Paper SPE 14253 Presented at the 60th Annual Technical Conference and Exhibition of the Society of Petroleum Engineers hled in Las Vegas, NY.

12. El-Khatib, N.A.F., 16-19 Nov. 1991. New Correlations for Time Lag and Pressure Response Amplitude in Pulse-Test Analysis, Paper SPE 21404 Presented at SPE Middle East Oil Show held in Bahrain.

13. Kamal, M.M., Aug. 1979. The Use of Pressure Transients to Describe Reservoir Heterogeneity, JPT, Trans., AIME, 267, pp. 1060-70.

14. Saeedi, J., Jan.-Feb. 1989. Layer Pulse Testing Using the Repeat Formation Tester, J. Cdn. Pet. Tech., pp. 126-134.

15. Bourdet, D., March 27-29, 1985. Pressure Behaviour of Layered Reservoirs with Cross-flow, Paper SPE 13628 Presented at the SPE California Regional Meeting, Bakersfield.

16. Kaneda, R., Saeedi, J., and Ayestran, L., Dec. 1991. Interpretation of a Pulse Test in a Layered Reservoir, SPEFE, pp. 453-62.

17. Matthews, C.S. and Russell, D.G., 1967. Pressure Buildup and Flow Tests in Wells, Monograph Series, SPE of AIME, Dallas, Texas, Vol. 1. 